\title{
PELATIHAN PENGELOLAAN WISATA DI KAMPUNG CABE DAN URBAN FARMING
}

\author{
Mutawali, Andriyani Hapsari, Mutawali, Vidya Amalia Rismanty, \\ Arief Rachman Akbar \\ Program Studi Manajemen \\ Universitas Pamulang \\ dosen01175@unpam.ac.id
}

\begin{abstract}
The purpose of this service is to formulate a strategy and action plan for development of the Chili Agriculture Education Tourism Village in Kabasiran Village, Parung Panjang District, Bogor Regency. This service uses an education and training approach for Kabasiran villagers, PT Evia's support team and PT Evia owners to make them ready with the village tourism program in the Kabasiran village area. Action Research and actions taken are together with elements of the community to hold discussions to analyze the strengths, weaknesses, potentials and threats in building a tourism village, formulating a business model for a tourist village to be built, discussion with farmer groups involved in the chilli cultivation process, and organizing counseling for the community. From the results of this training it was concluded that they were optimistic about the implementation of the chili tourism village program in Kabasiran village. From the villagers of Kabasiran ready to assist the implementation of the tourism village and ready to provide land for the interests of the tourism village, PT Evia's support team is ready with the budget to develop the chilli tourism village and has known the market target and marketing strategy of this tourism village from the owner of PT Evia will coordinate with the government to accelerate the integration of kabasiran tourism villages and is consistent with this tourism village program.
\end{abstract}

Keywords: Training and Education, Tourism Village, Community Based Tourism.

\begin{abstract}
Abstrak
Tujuan pengabdian ini adalah merumuskan strategi dan rencana aksi pembangunan Desa Wisata Edukasi Agrikultur Cabe di Desa Kabasiran, Kecamatan Parung Panjang, Kabupaten Bogor. Pengabdian ini menggunakan pendekatan edukasi dan pelatihan kepada warga desa kabasiran, tim support pt evia dan pemilik PT evia untuk menjadikan
\end{abstract}


mereka siap dengan adanya program desa wisata di wilayah desa kabasiran. Penelitian Aksi dan tindakan yang dilakukan adalah bersama dengan unsur masyarakat melakukan diskusi untuk menganalisa kekuatan, kelemahan, potensi dan ancaman dalam membangun desa wisata, merumuskan model bisnis desa wisata yang akan dibangun, diskusi dengan kelompok tani yang terlibat dalam proses budi daya cabe, dan menyelenggarakan penyuluhan untuk masyarakat. Dari hasil pelatihan ini disimpulkan bahwa mereka optimis dengan terlaksananya program desa wisata cabai di desa kabasiran. Dari warga desa kabasiran siap membantu pelaksanaan desa wisata dan siap menyediakan lahan untuk kepentingan desa wisata. Dari tim support PT Evia sudah siap dengan anggaran untuk mengembangkan desa wisata cabai dan sudah mengetahui sasaran pasar dan strategi pemasaran desa wisata ini dari pemilik PT Evia akan mengkoordinasi dengan pemerintah untuk mengakselerasi tercipatanya desa wisata kabasiran dan konsisten dengan program desa wisata ini.

\section{Kata Kunci : Pelatihan dan Edukasi, Desa Wisata, Pariwisata Berbasis Masyarkat.}

\section{A. PENDAHULUAN}

Parung Panjang merupakan kecamatan daerah pinggiran yang merupakan bagian dari kawasan kabupaten bogor, memiliki jarak sekitar $87 \mathrm{~km}$ dari ibukota kabupaten. Desa kabasiran merupakan bagian dari desa yang ada di wilayah parung panjang dari 11 desa serta merupakan desa terkecil dengan luas wilayah hanya $3,32 \mathrm{~km}^{2}$, dan memiliki status sebagai desa perkotaan. Desa ini memiliki populasi Jumlah penduduk desa sebesar 13.238 jiwa pada tahun 2016. Terdiri dari penduduk asli dan pendatang yang tinggal di perumahan-perumahan mulai dari perumahan sederhana hingga perumahan elit. Jika dilihat dari Indeks Pembangunan Manusia, Kecamatan Parung Panjang berada di angka 71,29 dengan angka harapan hidup 71,40 harapan lama sekolah 10,93 dan rata-rata lama sekolah 7,18. Artinya untuk penduduk berusia 25 tahun ke atas rata-rata lama sekolah penduduk kecamatan ini adalah 7,18 tahun atau berhenti sampai pertengahan SMP. Sementara harapan lama sekolah untuk penduduk 7 tahun ke atas adalah 10,93 tahun. Hal ini sejalan dengan pengamatan penulis bahwa tingkat pendidikan penduduk asli di Desa Kabasiran masih rendah, yaitu mayoritas hanya lulusan SD. Hal ini berakibat pada mata pencahariannya yaitu menjadi buruh kasar dan buruh cuci gosok/ asisten rumah tangga bagi yang perempuan dengan gaji Rp. 400.000 - 500.000/ bulan. Disamping itu mata pencaharian lain di desa ini, warga di desa kabasiran cukup produktif, mereka cukup produktif dalam memproduksi barang olahan yang memiliki nilai cukup tinggi, seperti membuat roti, pempek, peyek, bon Cabe, susu murni, membuat asesoris perhiasan, menanam Cabe. Hasil dari olahan tersebut selain mereka konsumsi sendiri juga di jual, namun hasil penjualannya belum cukup membantu perekonomian menjadi lebih baik karena keterbatasan pengetahuan akan pengolahan produksi yang tepat, serta pemasaran yang hanya dilakukan di satu komunitas. 
Bu Evie merupakan salah seorang tokoh masyarakat di Desa Kabasiran yang sukses menjalani usahanya dan sudah mendirikan perusahaan bernama PT. Evia Maju Bersama. Produk yang sudah berhasil dikembangkan adalah Abon Cabe dan beberapa olahan dari cabe. Pengembangan usaha ini Bu Evie melibatkan masyarakat, mulai dari proses pembibitan, pembudidayaan pohon cabe hingga produksi dan penjualan Abon Cabe. Keberhasilan $\mathrm{Bu}$ Evie ini, telah melibatkan masyarakat di dua RT untuk pembudidayaan cabe, dengan memberikan 30 polybag kepada 10 rumah. Jika panen maka Bu Evie akan membeli cabe dengan harga Rp.15.000/kg. Apabila panen tidak mencapai $1 \mathrm{~kg}$, maka Bu Evie memberlakukan sistem menabung cabe. Jadi berapa pun hasil panen yang diberikan masyarakat, uangnya tidak langsung dibayarkan oleh Bu Evie melainkan ditabung. Saat ini kebutuhan bu Evie untuk melayani permintaan dari konsumennya adalah $10 \mathrm{~kg} / \mathrm{hari}$ bahkan kadang kala sampai $20 \mathrm{~kg} / \mathrm{hari}$. Sementara yang mampu dipenuhi dari masyarakat binaannya hanya $2 \mathrm{~kg} /$ hari, sisa kekurangannya dipenuhi dengan membeli cabe di pasar. Untuk itu $\mathrm{Bu}$ Evie berencana mengembangkan usahanya dengan melibatkan lebih banyak lagi masyarakat yaitu remaja karang taruna untuk proses pembibitan dan $500 \mathrm{KK}$ untuk pembudidayaan cabe. Selain menjual produk Abon Cabe, tempat usaha Bu Evie ini juga sering dijadikan tempat destinasi belajar pengembangan UKM.

Melihat besarnya potensi dan kepedulian untuk bisa mengangkat perekonomian desanya, kemudian juga bisa dikembangkan sebagai destinasi wisata edukasi berbasis masyarakat maka besar kemungkinan Desa Kabasiran memiliki potensi dapat dikembangkan menjadi desa Wisata. Diharapkan dengan adanya desa Wisata ini potensi-potensi daerah dapat dikembangkan, terbukanya lapangan kerja baru, sehingga meningkatkan ekonomi dan kesejahteraan masyarakat lokal. Menurut Oka A. Yoeti (2002), pengembangan desa wisata sangat membantu peningkatan usaha dari kondisi masyarakat berpendapatan rendah. Peningkatan pendapatan ini berupa memanfaatkan hasil kerajinan tangan hasil pertanian, produk hasil seni dan budaya tradisional.

Pada pembentukan desa wisata, sangat dibutuhkan kriteria yang jelas. Jika sudah mampu memberikan klasifikasi desa wisata, maka dalam menyusun program kerja akan mudah dibedakan antara satu desa wisata dengan desa wisata lainnya. Kritera yang harus dibangun adalah perlu adanya pembinaan ke warga untuk menciptakan desa itu menjadi desa wisata, serta adanya kerja keras dari pemerintah kabupaten atau kota untuk bisa mensosialisasikan tentang pariwisata serta hal-hal yang dibutuhkan masyarakat mewujudkan pariwisata terus berkembang di desa itu. (Manhati, 2016).

Pembentukan desa wisata Cabe pada desa kebasiran parung panjang perlu dilakukan, karena telah memiliki potensi yang sangat baik dengan adanya Bu Evie sebagai salah satu tokoh masyarakat yang berhasil menciptakan aneka olahan unik dari Cabe, dan berhasil membina tokoh masyarakat di desa itu untuk terlibat dalam menanam Cabe dan melakukan produksi dari daerah itu. Di samping itu desa kabasiran juga belum memiliki wisata lain dan tidak ada konsep desa wisata Cabe. Menurut Hasbullah Asyari dikuti dari Yohanes Sulistyadi (2019), kesuksesan desa wisata tercermin dari adanya dukungan dari seluruh anggota masyarakat, seperti kepala keluarga, ibu-ibu rumah tangga, pemuda, dan anak anak.

Dalam membentuk Desa Kabasiran menjadi desa wisata Cabe perlu adanya analisa lebih mendalam sehingga mampu tersusun perencanaan strategis untuk bisa memberikan kejelasan konsep perencanaan yang harus diutamakan. Untuk syarat dalam pembangunan 
wisata terpenuhi. Menurut Kementrian Kebudayaan dan Pariwisata dikuti dari Yohanes Sulistyadi (2019), syarat dalam membangun desa wisata yaitu adanya daya tarik yang unik dan khas yang mampu dikembangkan sebagai daya tarik kunjungan wisatawan (sumber daya wisata alam, sosial, dan budaya); memiliki dukungan ketersediaan SDM (Sumber Daya Manusia) lokal; memiliki alokasi ruang untuk pengembangan fasilitas pendukung, seperti sarana dan prasarana berupa komunikasi dan akomodasi, serta Aksebilitas yang baik.

Oleh karena itu perlu dibuat pada permasalahan ini, yaitu terkait kondisi sosial budaya dan masyarakat (SDM) di Desa Kabasiran dalam kaitannya dengan usaha untuk mengembangkan Desa Wisata Edukasi Agrikultur Cabe; edukasi terhadap masyarakat yang dapat berpartisipasi dalam mendukung terealisasinya Desa Wisata Edukasi Agrikultur Cabe; dan Strategi yang harus diterapkan dalam pengembangan dan pengelolaan Desa Wisata Edukasi Agrikultur Cabe yang sesuai dengan konsep pariwisata berbasis masyarakat (community based tourism). Dari pelatihan ini menjadikan warga desa kabasiran menjadi lebih mandiri, kreatif dan memiliki perbaikan taraf hidup perekenonomian serta menjadikan desa kabasiran menjadi desa wisata yang unik di daerah parung panjang yang menjadikan sebagai konsep urban farmining dengan pendekatan cabai sebagai focus dari pengembanan desa wisata ini dan menjadi pioner di wilayah parung panjang.

\section{B. METODE PELAKSANAAN KEGIATAN}

Metode yang digunakan pada kegiatan pengabdian ini menggunakan pendekatan edukasi dan pelatihan. Edukasi yang peneliti lakukan dengan memberikan informasi tentang konsep dari pendirian desa wisata, yang diawali dengan perencanaan, pengorganisasian, pelaksanaan dan evaluasi dari hasil kegiatan. Peneliti juga memberikan dampak positif dan negative adanya desa wisata. Edukasi berikutnya peneliti juga memberikan gambaran anggaran yang harus disiapkan dalam melaksanakan program desa wisata, kegiatan di desa wisata dan bentuk kerjasama yang harus dilakukan untuk mengakselerasi desa wisata menjadi lebih baik. Tidak menutup kemungkinan dari edukasi ini, peneliti juga melakukan pelatihan khusus dan mengajak kepada warga desa kabasiran untuk berpatisipasi aktif dari penguasaan teori tentang budidaya cabai mulai dari pemiihan benih cabai, penanaman cabai, perawatan,dan pengololaan cabai saat sudah panen yang bisa diolah menjadi variasi produk makanan.

\section{HASIL DAN PEMBAHASAN}

Pelatihan desa wisata yang peneliti lakukan di desa kabasiran parung panjang merupakan pelatihan dasar yang dilakukan untuk warga, khususnya tim partner dari PT Evia yang sudah lama mengembangkan produk cabai dari penanaman cabai hingga pengolahan cabai menjadi produk makanan. Peneliti sudah memberikan edukasi kepada mereka untuk menjadi lebih baik lagi kualitas yang dimiliki mereka dalam mengolah cabai dan menjadikan desa ini sebagai desa wisata. Edukasi yang peneliti lakukan berupa tiga pelatihan dasar untuk pemiliki PT evia, tim support PT evia dan warga desa kabasiran. Diadakan pelatihan ini merupakan pemecahan masalah dari warga di sana yang mayoritas tidak memiliki pendidikan tinggi. Mayoritas warga di sana adalah lulusan smp. Disamping itu juga mereka juga tidak memiliki pendapatan yang tetap. Pendapatan yang diperoleh di bawah dari standar umr yang 
ditetapkan pemerintah. Sehingga bisa dikatakan warga di sana tergolong sebagai warga miskin.

Dengan adanya keterbatasan ini hasil dari penelitian ini, peneliti takjub dengan semgat juang mereka mempertahankan kehidupannya dalam mengkreasikan diri menciptakan sesuatu yang bisa dijadikan produk siap jual. Warga desa kabasiran sangat kreatif dalam mengolah bahan makanan menjadikan olahan yang memberikan nilai jual tinggi, bahan dasar yang mereka gunakan hanya dari cabai yang menjadi produk unggulan di desa ini. Cabai yang ia dapatkan dari hasil panen, mereka olah menjadi aneka produk makanan, seperti kripik cabai, pempek, coklat cabai, minyak saur pedas, bon cabai dan sebagainya. Tidak hanya olahan dari cabai saja yang mereka gunakan sebagai produk olahan siap jual. Mereka juga memiliki potensi dalam membuat minuman susu dengan kemasan kekinian, aneka olahan roti, serta olahan kue basah.

Desa ini yang menjadi cabai sebagai produk unggulan merupakan bentuk kerja keras dari PT evia yang memberikan edukasi lebih awal dengan mempelajari cara menanam cabai dan mengolah produk cabai. PT evia juga sudah banyak dikunjungi oleh mahasiswa dari kampus lain untuk menjadikan PT evia sebagai sumber penelitian. Tidak hanya itu,dari media televise di lapotop si unyil, kick andy, PT evia juga banyak diliput sebagai pengusaha terbaik dan kreatif dalam pengolahan cabai. Yang paling banyak dicari dari mereka di PT evia adalah cara mengelola cabai menjadi olahan variasi produk yang memiliki nilai jual yang tinggi dan cara dalam menanam cabai. Atas dasar penggagas dari PT evia menjadikan desa kabasiran maju dengan adanya bantuan dari PT evia memberikan lahan pekerjaan ke mereka dan membawa harum nama kampung halamannya. Konsep pengembangan desa cabai, peneliti coba mengembangkan menjadi desa wisata cabai di desa kabasiran yang belum pernah ada di tanah air Indonesia. Hal ini dikarenakan sudah punya dasar dari usaha yang dilakukan oleh PT Evia. Dari basic yang sudah dimiliki PT evia, peneliti akan melakukan kerjasama membangung desa wisata yang bekerjasama dengan PT Evia dengan mengadakan pelatihan selama tiga kali.Adapun pelatihan yang sudah dilakukan oleh peneliti adalah sebagai berikut:

1. Pelatihan pada tanggal 20 Oktober 2019

Pelatihan ini ditujukan kepada warga desa kabasiran parung panjang. Peneliti memberikan pelatihan berupa konsep dasar desa wisata dan budidaya cabai serta pengolahan cabai. Dalam memberikan konsep dasar desa wisata, peneliti telah memberikan gambaran usaha yang harus dilakukan untuk menjadikan desa ini sebagai desa wisata berupa potensi yang dimilikinya dan kerjasama yang baik. Peneliti memberikan gambaran potensi usaha yang bisa diambil dari desa wisata tersebut. Berupa penyediaan lahan parkir, penginapan, wc umum, penyediaan lahan pertanian cabai, museum cabai, pengolahan cabai, souvenir, dll. Potensi usaha ini peneliti uraikan dampak baik buruk ketika memiliki usaha itu dan upaya dalam mengatasi permasalahan itu. Seperti penyediaan lahan parkir, perlu ada pembebasan lahan kosong untuk disediakan lahan parkir, serta perlu adanya konsistensi dalam menjaga keamanan kendaraan para pengunjung agar tidak sampai terjadi kehilangan. Masalah keamanan, perlu adanya kewaspadaan terjadi pencurian, kriminalitas dari sisi pengunjung dan warga di sana. Pemberian deskripsi usaha ini menjadikan warga di sana memiliki rasa tanggung jawab jika mereka menjadi bagian dari pekerjaan tersebut. Disamping itu peneliti juga memberikan edukasi kepada mereka tentang cara menanam cabai sebagai produk 
unggulan di desa ini. Warga di sana harus bisa menjaga kelestarian cabai dan memperbanyak pembibitan cabai dan memperindah lingkungan di desa tersebut banyak cabai indah yang tertanam serta upaya pada saat terjadi permasalahan pada cabai tersebut yang terkena hama, perawatan, dan lain sebagainya.

2. Pelatihan tanggal 27 Oktober 2019

Pelatihan kedua peneliti tunjukkan kepada tim support PT Evia. Peneliti memfokuskan pelatihan ini untuk merencanakan anggaran yang dibuat dalam pembentukan desa wisata cabai. Anggaran ini ditujukan untuk melihat permulaaan saat mengerjakan desa ini menjadi wisata, seperti anggaran dalam pengolahan lahan tanam cabai, membuat museum cabai, spot wisata cabai souvenir cabai, dll. Selanjutnya peneliti juga melakukan pelatihan terkait masalah sasaran pasar desa wisata ini dan media pemasaran untuk mempromosikan desa ini menjadi kota wisata. Pelatihan berikut nya melakukan mengkuatkan produk unggulan di desa kabasiran berupa cabai sebagai produk utama, harus ada kerjasama dari tim support memberikan edukasi ke masyarakat desa kabasiran tentang cara pengolahan dan penanaman cabai

3. Pelatihan tanggal 3 November 2019

Pelatihan yang terakhir peneliti melakukan pelatihan kepada pemilik pt evia dan tim support pt evia. Materi edukasi yang disampaikan pada pelatihan ini berupa motivasi seorang dalam mendirikan desa yang dibangun dengan berlandaskan konsistensi, tahap terhadap semua permasalahan dan berani mengambil risiko dari permasalahan yang nanti nya akan dihadapi saat terselenggaranya desa wisata ini. Selanjutnya peneliti juga memberikan edukasi mengenai pentingnya kerjasama dengan pemerintah dalam mendirkan desa wisata. Agar mendapat banyak bantuan berupa moril dan materil untuk mempercepat terselenggaranya desa ini menjadi desa wisata serta mempermudah segala macam bentuk izin saat proses pendirian desa wisata dan berjalannya desa wisata.

\section{KESIMPULAN DAN SARAN}

\section{Kesimpulan}

1. Menjadikan warga desa kabasiran menjadi lebih meyakini dengan terlaksananya program desa wisata cabai di desa kabasiran dan sangat mendukung terlaksananya desa ini menjadi desa wisata cabai. Disamping itu mereka sudah sangat siap menyediakan prasarana untuk para pengunjung dan siap memberikan pelayanan terbaik untuk para pengunjung.

2. Tim support PT evia menjadi semakin yakin dengan terlaksananya program desa wisata ini dengan perencanaan anggaran yang sudah diestimasikan, sasaran pasar dan media pemasaran yang sudah didapat dari edukasi ini.

3. Pemilik PT Evia merasa terbantu dengan mendongkrak nama baik ini dalam memajukan desa ini menjadi desa wisata produk unggulan PT evia. Serta mendapat penerangan PT evia dalam bekerjasama dengan pemerintah untuk mengakselerasi desa wisata ini menjadi sebuah kenyataan di desa kabasiran.

\section{Saran}

Atas dasar pelatihan yang sudah diberikan oleh tim peneliti. Langsung dipraktikan dalam pelaksanaan program desa wisata, agar semua ilmu yang sudah didapatkan dari 
edukasi ini bisa memberi manfaat dalam mengembangkan desa kabasiran menjadi desa yang maju denga adanya desa wisata cabai.

\section{DAFTAR PUSTAKA}

Adawiyah, R., dkk. (2017). Strategi Pengembangan Desa Wisata Berbasis Masyarakat (Community Based Rural Tourism) di Desa Papringan. Prosiding Seminar Nasional; Universitas Jenderal Soedirman.

Alam (2006). Ekonomi Untuk SMA dan MA. PT. Gelora Aksara Pratama. Jakarta

Budiarti, T., dkk. (2013). Pengembangan Agrowisata Berbasis Masyarakat pada Usahatani Terpadu Guna Meningkatkan Kesejahteraan Petani dan Keberlanjutan Sistem Pertanian. Jurnal Ilmu Pertanian Indonesia (JIPI) Vol 18 (3): 200-207.

Istiqomah dan Andriyanto, I. (2017). Analisis SWOT dalam Pengembangan Bisnis (Studi pada Sentra Jenang di Desa Wisata Kaliputu Kudus) Bisnis, Vol. 5 No. 2 Desember.

Marimin. (2004). Teknik dan Aplikasi Pengambilan keputusan Kriteria Majemuk, Grasindo, Jakarta.

Nurisjah S. (2001). Pengembangan kawasan wisata agro (Agrotourism). Buletin Tanaman dan Lanskap Indonesia. 4(2): 20-23.

Picard, M. (2006). Bali: Pariwisata Budaya dan Budaya Pariwisata, Kepustakaan Pupuler Gramedia, Jakarta.

Prastiwi, S. M, (2016). Manajemen Strategis Dinas Kebudayaan dan Pariwisata Kabupaten Bojonegoro Dalam Mengembangkan Potensi Objek Wisata Edukasi Little Teksas Wonocolo. Publika Vol 4 No. 11.

Rangkuti, F. (2004). Analisis SWOT Teknik membedah Kasus Bisnis, PT. Gradia, Jakarta.

Simanjuntak, T., dkk. (2016) Karawang Dalam Lintasan Peradaban Pusat Jakarta.Penelitian Arkeologi Nasional

Solihin, D. (2020), Faktor-Faktor Yang Mempengaruhi Kinerja Pemasaran Pada PT Prima Ufuk Semesta (Studi Empiris Pada Outlet Rekanan PT. Prima Ufuk Semesta Di Wilayah Jabodetabek), Jurnal Semarak, Vol. 3. No. 1.

Sucahyowati, H. (2017). Pengantar Manajemen. Wilis

Sulistyadi, dkk. (2019). Pariwisata Berkelanjutan dalam Perspektif Pariwisata Budaya di Taman Hutan Raya Banten, Uwais Inspirasi Indonesia, Ponorogo.

Thomson. (2007). Pengantar Bisnis: Kontemporer, Edisi 11. 2007.

Ulung, G. (2009). Liburan Murah Meriah di Jogja, PT. Gramedia Pustaka Utama, Jakarta.

Yoeti, O. A. (2002). Ekonomi Pariwisata Introduksi, Informasi, dan Aplikasi, Kompas, Jakarta.

Zebua, M. (2016). Inspirasi Pengembangan Pariwisata Daerah, Deepublish, Yogyakarta. 